\title{
AVALIAÇÃO DO SISTEMA DE TRATAMENTO DE EFLUENTES GERADOS EM INDÚSTRIA DE LATICÍNIOS
}

\author{
EVALUATION OF THE SYSTEM OF TREATMENT OF EFFLUENTS \\ GENERATED IN THE WASTE INDUSTRY
}

\author{
Vinícius Marques Gomes, Daniel Ângelo Macena, Ana Beatriz Hossaka, \\ Anderson Luis De Mattos Bezerra, Amandio Oliveira da Silva Júnior \\ Universidade do Oeste Paulista - UNOESTE, Curso de Química Bacharelado, Presidente \\ Prudente, São Paulo. \\ e-mail: daniel@unoeste.br
}

RESUMO - A avaliação da eficiência do tratamento de efluentes é muito importante em se tratando do reuso da água industrial. Diariamente, as atividades industriais geram resíduos sólidos e líquidos, conhecidos como efluentes industriais. Este trabalho avaliou a eficiência do tratamento dos efluentes gerados por um laticínio da região de Presidente Prudente/SP a fim de verificar se o mesmo está apto a ser lançado na rede de esgotos para prosseguir seu tratamento final. O laticínio em questão lança seus efluentes na rede de coleta de esgotos da Companhia de Saneamento Básico do Estado de São Paulo - Sabesp e, para que esse processo seja feito de forma adequada, o Decreto no 8.468/76 determina valores máximos permitidos para parâmetros como Demanda Biológica de Oxigênio, Demanda Química de Oxigênio, pH, Teor de Óleos e Graxas e Sólidos Sedimentáveis. As amostras foram coletadas na estação de tratamento da empresa e as análises foram feitas com base no Standard Methods of Water and Wastewater, que descreve os métodos analíticos padrão para água e esgoto. Tendo em vista a conformidade dos resultados obtidos nas análises foi possível confirmar que o tratamento realizado pelo laticínio é eficiente e atende à legislação vigente.

Palavras-chave: efluente; poluentes; tratamento.

ABSTRACT - The evaluation of the effluent treatment efficiency is very important when it comes to industrial water reuse. On a daily basis, industrial activities generate solid and liquid waste, known as industrial effluents. This work evaluated the efficiency of the treatment of the effluents generated by a dairy in the region of Presidente Prudente / SP in order to verify if it is able to be released in the sewage network to continue its final treatment. The dairy in question launches its effluents into the sewage collection network of the São Paulo State Sewage Company - Sabesp and, in order for this process to be properly carried out, Decree No. 8.468 / 76 determines maximum permitted values for parameters such as Biological Demand of Oxygen, Chemical Oxygen Demand, pH, Oils and Grease Content and Sedimented Solids. Samples were collected at the company's treatment plant and analyzes were done based on Standard Methods of Water and Wastewater, which describes the standard analytical methods for water and sewage. In view of the conformity of the results obtained in the analyzes it was possible to determine that the treatment performed by the dairy is effective and complies with the current legislation.

Revisado em: 29/08/2017

Aprovado em: 04/09/2017 


\section{INTRODUÇÃO}

O Brasil é um dos maiores produtores de leite do mundo segundo a Secretaria de Estado da Agricultura e do Abastecimento. A produção brasileira de leite no ano de 2014 foi de 33,4 milhões de litros, fazendo assim com que o Brasil ocupasse a quinta posição no ranking mundial, ficando atrás da União Europeia, Índia, Estados Unidos e China (SEAB, 2014). Dados do Instituto Brasileiro de Geografia e Estatística - IBGE estimam um crescimento de $2 \%$ na produção de leite do Brasil (BRASIL, 2015).

Nas indústrias de leite podem ser fabricados diversos produtos, como, por exemplo, leite em pó, leite UHT ou UAT (Ultra High Temperature, ou Ultra Alta Temperatura respectivamente), cremes, queijos, etc. Em uma indústria de laticínios são aplicados diversos processos para o tratamento do leite, uma delas é a pasteurização, tratamento térmico que visa à eliminação de bactérias patogênicas do leite. Este processo é indispensável e obrigatório. Todos os derivados devem ser fabricados a partir de leite pasteurizado (PORTO, 2007).

Outro processo muito utilizado para tratamento do leite é o processamento UHT. Neste processo, o leite cru, após passar por analises laboratoriais, é pasteurizado, tratado por ultra alta temperatura através da injeção por vapor direto da água e homogeneizado. O processo UHT garante ao produto um longo período de vida comercial, além de maximizar a eliminação de microrganismos (MARTINS et al., 2008).

Diariamente, as atividades industriais geram resíduos sólidos e líquidos, conhecidos como efluentes industriais. A água pode ser utilizada nas indústrias de diversas formas, tais como: lavagens de máquinas, tubulações e pisos, sistemas de resfriamento, geradores de vapor, águas utilizadas diariamente nas etapas do processo industrial e esgotos sanitários. Um exemplo do uso da água no processo industrial de um laticínio é a pasteurização, tratamento térmico citado anteriormente, onde o leite é aquecido com o auxílio de água quente entre 63 a $95^{\circ} \mathrm{C}$, dependendo do tipo de pasteurização empregada e, logo em seguida, sofre um choque térmico com o auxílio de água gelada, sendo resfriado até a temperatura de 3 a $4^{\circ} \mathrm{C}$ (AMORIM, 2014).

A água utilizada no processo industrial, exceto pelas perdas de volume por volatilização e pelos volumes de água incorporados aos produtos, é contaminada por diversos resíduos originando os efluentes industriais. Para que estes resíduos líquidos sejam descartados em corpos d'água devem passar por um tratamento adequado, pois os efluentes gerados por indústrias de laticínios possuem alto teor de matéria orgânica em sua composição e, se despejados com os seus poluentes característicos, causam alteração 
da qualidade nos corpos receptores e, consequentemente, a sua poluição (AMORIM, 2014).

Segundo dados do Censo Agropecuário de 2006 do Instituto Brasileiro de Geografia e Estatística, o de Presidente Prudente município possui 806 unidades de estabelecimentos agropecuários, dentre estes estabelecimentos, 2 empresas são do ramo de laticínios. Um dos laticínios comercializa somente dentro do município, já o outro comercializa em nível nacional. Esta segunda empresa produz, em média, aproximadamente 300 mil litros de leite UHT e tem um gasto médio de 28 mil litros de água por hora no seu processo industrial.

O efluente lançado por este laticínio é recolhido por tubulação e enviada para a Estação de Tratamento de Efluente localizada dentro da empresa. O tratamento é feito através de lagoas facultativas, que são lagoas que trabalham com condições aeróbias e anaeróbias. Neste tratamento, as condições aeróbias são mantidas nas camadas superiores e as condições anaeróbias nas camadas inferiores da lagoa (SABESP, 2009).

Atualmente a empresa trabalha com três variáveis no efluente. Sendo eles: consumir a matéria orgânica, clarificar o efluente e atingir os parâmetros estabelecidos em contrato com a Companhia de Saneamento Básico do Estado de São Paulo (SABESP), responsável pelo recebimento do efluente tratado. A avaliação da eficiência do tratamento de efluentes é muito importante, tratando-se de reuso da água industrial. 0 panorama de disponibilidade de água disponível para o uso humano vem piorando, portanto, ideias que ajudem a inovar e melhorar o tratamento de poluentes é visto como a solução para esta "crise de água" que se vive.

Portanto, este trabalho teve como objetivo analisar se o efluente lançado por um determinado laticínio está dentro dos parâmetros exigidos pela SABESP verificar se está apto para ser recebido no sistema da Sabesp, que irá finalizar o tratamento para que a água seja adequadamente retornada à população. Os parâmetros estabelecidos pela empresa estão baseados no Decreto no $8.468 / 76$, que dispõe sobre a prevenção do meio ambiente, do Ministério do Meio Ambiente.

\section{METODOLOGIA}

As amostras foram coletadas em dois pontos: antes dos efluentes serem lançados na lagoa de tratamento do laticínio (efluente bruto), e após serem tratados pela estação de tratamento da própria empresa (efluente tratado). Foi realizada uma amostragem composta em ambos os pontos de coleta durante três dias. As amostras foram compostas a fim de obter uma maior representatividade dos efluentes, pois 0 mesmo sofre alteração de carga de 
contaminantes em função da rotina de produção do laticínio (SPERLING, 1996).

Com o auxílio de um béquer, com capacidade volumétrica de 1 litro, três alíquotas de mesmo volume foram coletadas, em um período de 8 horas, em cada ponto de coleta e armazenadas em um frasco de 5 litros em local refrigerado. Após a composição de duas amostras (amostra composta do efluente bruto e amostra composta do efluente tratado), estas foram transferidas para frascos de vidro âmbar, com capacidade volumétrica de 1 litro, previamente identificados, totalizando 3 frascos para cada ponto. As amostras foram refrigeradas e preservadas de acordo com as recomendações estabelecidas pela AMERICAN PUBLIC HEALTH ASSOCIATION APHA (2005). O mesmo procedimento foi realizado para a coleta dos outros dois dias, compondo as amostras B1 (efluente bruto 10 dia), T1 (efluente tratado - 10 dia), B2 (efluente bruto - 2o dia), T2 (efluente tratado - 2ㅇ dia), B3 (efluente bruto - 3 dia) e T3 (efluente tratado - 3ㅇdia). Todas as análises foram realizadas de acordo com a indicada pelo Satandard Methods for the examination of Water and Wastewater 21a edição (APHA, 2005).

Para aferição do $\mathrm{pH}$ (potencial hidrogeniônico) foi utilizado método potenciométrico (Standard Methods 4500 $\mathrm{H}+: 2)$ que tem como princípio a determinação da concentração da espécie iônica a partir da medida do potencial elétrico. Foi utilizado um aparelho pHmetro (marca Quimis), que possui um eletrodo combinado para $\mathrm{pH}$ e um sensor de temperatura. O aparelho foi devidamente calibrado com três soluções tampão de pH conhecido, $\mathrm{pH} 4,01$, pH 6,86 e pH 9,18.

A Demanda Química de Oxigênio (DQO) é um parâmetro que permite a estimativa da concentração de contaminantes orgânicos na água. Como a degradação de compostos orgânicos utiliza o oxigênio, as concentrações destas substâncias podem ser obtidas pela quantidade de oxigênio requerida. A determinação da DQO trata-se de um método colorimétrico de refluxo fechado (Standard Methods - 5220 - D). O princípio desta análise consiste na oxidação química de redutores, utilizando-se o dicromato de potássio (K2Cr2O7). A reação ocorre a quente, em meio de ácido sulfúrico (H2SO4), sendo catalisada por sulfato de prata (Ag2SO4) e na presença de mercúrio (APHA, 2005).

Para a determinação da Demanda Biológica de Oxigênio (DBO), foi utilizado o método respiratório simplificado (Standard Methods 5210 - B), um bioensaio que consiste na incubação das amostras em garrafas de vidro âmbar específicas durante um período de cinco dias a uma temperatura 
controlada de $20^{\circ} \mathrm{C}$, na presença de microrganismos e ausência da luz. Por meio de agitação, o oxigênio presente na câmara de ar se dissolve no líquido. Os microrganismos utilizam este oxigênio durante o processo de degradação da matéria orgânica, eliminando gás carbônico e produzindo uma diferença de pressão na garrafa que é medido por sensor (Oxitop), cujo sistema identifica a redução de pressão provocada (APHA, 2005).

O método da análise de Óleos e Graxas (Standard Methods 5520 - D) referese à extração com solvente hexano pelo método de Soxhlet. Alguns extratos com solventes, principalmente gorduras, não saturados e ácidos graxas, se oxidam facilmente, as graxas incluem ceras, óleos e gorduras. O extrator Soxhlet é usado para separar os óleos e graxas do sulfato de magnésio hepta-hidratado e da matéria orgânica. Baseia-se em acidificar a amostra para a separação do óleo, insolubilizar qualquer sabão metálico e promover a quebra da emulsão. Em seguida, a amostra é filtrada e o filtro secado em estufa à $103^{\circ} \mathrm{C}$. Após a secagem, o cartucho é introduzido no extrator. O produto final é pesado para quantificação do teor de óleos e graxas na amostra (SABESP, 1997).

A determinação dos sólidos sedimentáveis (Standard Methods 2540 - F) promove-se pela homogeneização e decantação da amostra. A amostra é homogeneizada e a alíquota de 1 litro é transferida para o cone de Imhoff e decantada por 60 minutos. 0 resultado final se expressa diretamente na leitura do sedimentado pela escala graduada do cone de Imhoff (mL/L) (SABESP, 1997).

Por fim, a determinação dos sólidos totais (Standard Methods $2540-B$ ) envolve a secagem total de um determinado volume de amostra, em seguida a massa final é pesada, sendo desprezado a massa do recipiente utilizado, obtendo-se o valor de sólidos totais na amostra em mg/L (SABESP, 1997).

\section{RESULTADOS}


Tabela 1. Comparação de Resultados dos Efluentes Brutos e Tratados x VMP.

\begin{tabular}{|c|c|c|c|c|c|}
\hline Parâmetros & Unidade & DIA 1 & DIA 2 & DIA 3 & VMP \\
\hline $\mathrm{pH}^{*}$ Bruto & - & 10,88 & 9,56 & 10,10 & Entre 6 e 10 \\
\hline $\mathrm{pH}^{*}$ Tratado & - & 7,81 & 7,53 & 7,69 & \\
\hline DQO Bruto & $\mathrm{mg} / \mathrm{L}$ & 1016,66 & 913,33 & 123,33 & 800 \\
\hline $\mathrm{DQO}_{\text {Tratado }}$ & $\mathrm{mg} / \mathrm{L}$ & 423,33 & 526,66 & 656,66 & 800 \\
\hline DBO Bruto & $\mathrm{mg} / \mathrm{L}$ & 603,0 & 603,0 & 88,0 & 300 \\
\hline DBO Tratado & $\mathrm{mg} / \mathrm{L}$ & 210,0 & 190,0 & 150,0 & 300 \\
\hline TOG Bruto & $\mathrm{mg} / \mathrm{L}$ & 43,9 & 56,5 & 74,0 & 20 \\
\hline TOG Tratado & $\mathrm{mg} / \mathrm{L}$ & 16,4 & 63,9 & 18,6 & 20 \\
\hline SS Bruto & $\mathrm{mL} / \mathrm{L}$ & 0,1 & 0,1 & 0,5 & $<0,1$ \\
\hline $\mathrm{SS}_{\text {Tratado }}$ & $\mathrm{mL} / \mathrm{L}$ & $<0,1$ & $<0,1$ & $<0,1$ & $<0,1$ \\
\hline ST Bruto & $\mathrm{mg} / \mathrm{L}$ & 1136,0 & 1234,4 & 4418,0 & - \\
\hline ST Tratado & $\mathrm{mg} / \mathrm{L}$ & 1174,0 & 1058,0 & 1119,0 & - \\
\hline
\end{tabular}

Fonte: Próprio autor

Nota: VMP= Valor Máximo Permitido; TOG= Teor de Óleos e Graxas; SS= Sólidos Sedimentáveis e ST= Sólidos Totais.

Após a observação dos resultados obtidos nas análises laboratoriais (Tabela 1), foi possível determinar a eficiência ou ineficiência do sistema de tratamento utilizado na indústria de laticínio estudada durante o trabalho, com o auxílio de gráficos e tabela. Todos os valores gerados como resposta das análises foram comparados com - valor máximo permitido de cada parâmetro, que são estipulados pela SABESP, empresa que receberá o efluente e realizará seu tratamento final. Esta tem como embasamento legal o Decreto № 8.468, de 8 de setembro de 1976.

\section{DISCUSSÃO}

Em análise ao $\mathrm{pH}$ das amostras do efluente bruto, foi verificado que apenas uma amostra, B2, se encontrava dentro do limite aceitável. Após o tratamento realizado em ETE da empresa, foi observado que todas as amostras do efluente tratado se enquadram nos valores permitidos, mantendo uma média de $\mathrm{pH}$ 7,68, comprovando assim a eficiência na adequação do potencial hidrogênionico para um caráter levemente básico.

A remoção da matéria orgânica do efluente bruto é um dos principais objetivos do sistema de tratamento e apresenta resultados satisfatórios. Embora a amostra do terceiro dia, B3, tenha apresentado aumento na DQO e também na DBO, ainda houve um percentual médio positivo na remoção da matéria. Observa-se que tanto os valores de concentração de oxigênio obtidos na análise de DQO, como os valores da DBO, após receberam tratamento obtiveram um número abaixo do limite aceitável, apresentando uma média percentual de remoção de $54,43 \%$ e $21,75 \%$ respectivamente. 
O resultado do teor de óleos e graxas foi muito alto nas amostras de efluente bruto, obtendo uma média de 58,13 mg/L. Após o tratamento adquiriu valores abaixo do valor máximo permitido que era de 20 $\mathrm{mg} / \mathrm{L}$, exceto na amostra do efluente tratado do dia 2, porém, em média a remoção do teor de óleos e graxas do efluente obteve um percentual de $43,29 \%$. De maneira geral, as demais amostras não obtiveram um teor acima do permitido, uma vez que o teor em excesso só se torna alarmante se estiver constantemente alto, permitindo $\mathrm{o}$ prosseguimento do efluente gerado na indústria para uma estação de tratamento da empresa responsável pelo término da sua descontaminação.

O perfil da concentração de Sólidos Totais foi realizado para comprovar e auxiliar o parâmetro de Sólidos Sedimentáveis e, embora o decreto 8.468/1976 não estipule limites aceitáveis para esse parâmetro, ficou evidenciada a redução na carga de sólidos totais após o tratamento, como se observa nos dias 2 e 3.

Já na análise de Sólidos Sedimentáveis, observa-se uma nítida remoção da grande maioria destes sólidos, pois as análises dos efluentes tratados estão todas em conformidade com os valores máximos permitidos.

Resultados apresentados no trabalho "Tratamento de águas residuárias de indústria de laticínios: eficiência e análise de modelos matemáticos do projeto da Nestlè" (NIREMBERG; FERREIRA, 2005) indicaram a eficiência do sistema de tratamento da empresa. Através de análises dos parâmetros DBO, DQO, pH, sólidos totais dissolvidos, entre outros, foi comprovado que o sistema de tratamento com lagoas de estabilização da indústria analisada é eficaz, sugerindo ainda o incentivo à existência de estações de tratamento de esgotos em indústrias.

$\mathrm{O}$ artigo "O tratamento de águas residuais de indústria de laticínios: um estudo comparativo entre os métodos de tratamento com biofiltro e com o sistema convencional de lagoas" (SILVA; EYNG, 2013) apresenta resultados desfavoráveis à utilização do sistema convencional de lagoas para efluentes lançados em corpos hídricos, sendo favorável a utilização de filtros biológicos para o tratamento do efluente. Os parâmetros analisados foram semelhantes à este trabalho (DBO, DQO, $\mathrm{pH}$, óleos e graxas e sólidos sedimentáveis). Segundo os autores, a utilização do sistema de lagoas possui alto custo de manutenção, além da ocupação de grande espaço físico, causando odor desagradável e atraindo animais indesejáveis.

Embora alguns trabalhos apresentem resultados favoráveis e outros desfavoráveis, - sistema convencional de lagoas de estabilização é considerado o mais simples e 
comum no tratamento de esgotos. As principais vantagens deste sistema são a facilidade de construção, operação e manutenção com custos reduzidos, além da resistência a variações de carga, porém, como desvantagem, necessita de ampla área para construção (SPERLING 1996).

\section{CONCLUSÃO}

Ao término deste trabalho é possível concluir que o tratamento que está sendo realizado pela indústria de laticínio estudada é completamente eficaz, atendendo à principal dúvida deste estudo.

Comprova-se também a necessidade da realização do tratamento prévio realizado nas lagoas de aeração da indústria, pois sem ele o efluente não estaria apto para ser transferido para a ETE da Sabesp e causaria grandes danos ambientais caso fosse descartado em corpos receptores como rios e lagos.

As análises realizadas nos laboratórios da Universidade do Oeste Paulista (UNOESTE) comprovaram a qualidade do efluente tratado que foi recolhido na lagoa facultativa em dias diferentes, já que a grande maioria dos resultados apresentados das amostras estavam com os parâmetros de Potencial Hidrogeniônico $(\mathrm{pH})$, Sólidos Sedimentáveis e Totais, Demanda Biológica de Oxigênio (DBO), Demanda Química de Oxigênio (DQO), e Óleos e Graxas, em conformidade com o valor máximo permitido pela empresa recolhedora do efluente.

A empresa pode ainda contribuir para obtenção de resultados mais positivos, diminuindo a emissão de matéria orgânica, através da minimização de falhas em seu sistema produtivo, gerando assim menos resíduos.

\section{REFERÊNCIAS}

APHA - AMERICAN PUBLIC HEALTH ASSOCIATION. Standard methods for the examination of water \& wastewater. 21. ed. Washington, D.C., 2005.

AMORIM, R. F. Tratamento de efluentes em lagoas de estabilização: um estudo de caso em indústria de laticínio na região do Vale do Jamari - RO. 2014. $69 \mathrm{f}$.

BRASIL. Ministério do Meio Ambiente. Decreto n.o 8.468, de 8 de setembro de 1976 . Concede indulto, comuta penas e dá outras providências. Aprova o Regulamento da Lei no 997, de 31 de maio de 1976, que dispõe sobre a Prevenção e o Controle da Poluição do Meio Ambiente, São Paulo, SP, 9 set. 1976.

BRASIL. Ministério do Meio Ambiente. Decreto no 8.468/1976. Decreto Estadual. Disponível em: $<$ http://licenciamento.cetesb.sp.gov.br/Servi cos/licenciamento/postos/legislacao/Decreto _Estadual_8468_76.pdf>. Acesso em 15 set. 2015.

SABESP. Norma Técnica Interna SABESP: NTS 004 e 005. São Paulo, 1997.

SABESP. Norma Técnica Interna SABESP: NTS 013. São Paulo, 2009.

MARTINS, A. M. V. et al. Ciência e Tecnologia de Alimentos. Efeito do processamento UAT 
(Ultra alta Temperatura) sobre as características físico-químicas do leite. Campinas, jun., 2008.

NIREMBERG, L. P.; FERREIRA, O. M. Tratamento de águas residuárias de indústria de laticínios: eficiência e análise de modelos matemáticos do projeto da Nestlè: estudo de caso. 2005. $91 \mathrm{f}$. Trabalho de Conclusão de Curso (Graduação). Universidade Católica de Goiás, Goiânia-GO, 2005.

PORTO, E. Tratamento do leite. Pasteurização do Leite, Piracicaba, SP, nov., 2007.

SILVA, F. K; EYNG, J. O tratamento de águas residuais de indústria de laticínios: um estudo comparativo entre os métodos de tratamento com bioflitro e com o sistema convencional de lagoas. Artigo. Revista Gestão \& Sustentabilidade Ambiental, Florianópolis, v. 1, n. 2, p. 4-12, mar. 2013.

SPERLING, M. V. Introdução à qualidade das águas e ao tratamento de esgotos. 2 ed. Belo Horizonte: Departamento de Engenharia Sanitária e Ambiental; Universidade Federal de Minas Gerais. 1996. p. 169-191. 